\title{
CONGENITAL BICUSPID AORTIC VALVES: A CLINICAL AND HÆMODYNAMIC STUDY
}

\author{
BY \begin{abstract}
AND HARRY GOLDBERG
\end{abstract} \\ LAMBERTO G. BENTIVOGLIO, JAVIER SAGARMINAGA, JOSEPH URICCHIO,
}

\begin{abstract}
From the Brith Sholom Cardiopulmonary Laboratory, Hahnemann Medical College and Hospital and The Bailey Thoracic Clinic, Philadelphia, Pennsylvania
\end{abstract}

Received July 7, 1959

The first description of a congenital bicuspid aortic valve was made by Günsberg in the year 1846. The pathogenesis of this malformation has been ascribed either to fusion of two adjacent valvular edges during fotal life (Peacock, 1865) or to failure of a valvular cusp to develop (Peacock, 1866).

Early publications on this subject have dealt mainly with its embryological and pathological aspects (Günsburg, 1846; Peacock, 1865; Osler, 1866; Koletsky, 1941; Bettini, 1957), while clinical reports have been scanty and usually retrospective, the clue to a tentative intra vitam diagnosis usually being the implantation of subacute bacterial endocarditis upon a bicuspid aortic valve (Bourne, 1946; Tranchesi et al., 1954).

The introduction of left heart catheterization into clinical medicine (Björk et al., 1953) provided the opportunity of appraising the dynamics of this congenital malformation. The possibility, however, remained for some time only theoretical from lack of confirmation, either surgical or by necropsy. The difficulty has been overcome with the advent of open heart surgery which affords the opportunity for verification of the clinical diagnosis. The present report deals with the clinical, radiographic, electrocardiographic and hæmodynamic data of six proven cases of congenital bicuspid aortic valves, five of which were associated with varying degrees of commissural fusion.

\section{MATERIAL AND METHODS}

Three men and three women form the present group, their age ranging from 9 to 27 years. In each case clinical data were obtained as well as routine twelve-lead electrocardiograms and roentgenograms in the four conventional positions. Criteria for left ventricular hypertrophy were those of Sokolow and Lyon (1949): an S wave in V1 of $24 \mathrm{~mm}$. or more was also included in the criteria for left ventricular hypertrophy (Kossmann and Johnston, 1935).

Left heart catheterization alone was performed in two patients. In one of them the left heart needle was advanced into the right atrium on the first pass, so that also right atrial and ventricular pressures were available. One patient had right heart catheterization alone and three had left and right heart catheterization carried out at different times. Left heart catheterization was performed utilizing the technique employed in our laboratory (Bougas et al., 1956); right heart catheterization as described by Cournand and Ranges (1941). All pressures were recorded by means of Statham P23D strain gauge manometers on an electronic photo-oscillograph. The mean pressures were obtained by electronic integration at the time of catheterization. The cardiac output was determined by the direct Fick principle. Blood gas analysis was performed according to the technique of 
Van Slyke and Neill (1924). Aortic valve flows and areas were calculated employing the modified Gorlin and Gorlin formulæ (Gorlin and Gorlin, 1951; Goldberg et al., 1957). No patient was receiving digitalis at the time of the study.

Four patients were operated upon under hypothermia and two with the use of a pump oxygenator.* In all six, a transaortic approach was utilized and the aortic valve inspected and the obstruction, when present, relieved under direct vision.

\section{RESULTS}

In all patients the aortic murmur was discovered between birth and the age of five. Symptoms were absent in one and minimal in five, consisting of fatigue (3), exertional dyspnœa and obesity (1), and fatigue and exertional dyspnoa (1) (Table I).

The apical impulse had a normal location in all. A systolic thrill was present in the second right intercostal space in each case and its auscultatory equivalent was a grade III or IV rough systolic

TABLE I

Clinical Data in Bicuspid Aortic Valve

\begin{tabular}{|c|c|c|c|c|c|c|c|c|c|c|}
\hline \multirow[b]{2}{*}{ Name } & \multirow[b]{2}{*}{ Sex } & \multirow[b]{2}{*}{ Age } & \multirow[b]{2}{*}{ Symptoms } & \multicolumn{5}{|c|}{ Signs } & \multirow[b]{2}{*}{ Radiology } & \multirow[b]{2}{*}{ E.C. } \\
\hline & & & & $\mathbf{M}_{1}$ & $\mathbf{A}_{2}$ & $\begin{array}{l}\text { Aortic } \\
\text { systolic } \\
\text { thrill }\end{array}$ & $\begin{array}{l}\text { Aortic } \\
\text { systolic } \\
\text { murmur }\end{array}$ & $\begin{array}{c}\text { Aortic } \\
\text { diastolic } \\
\text { murmur }\end{array}$ & & \\
\hline R.T. & $\mathbf{M}$ & 6 & Slight fatigue & $\mathbf{N}$ & $\mathbf{N}$ & + & $\underset{3}{\text { Grade }}$ & - & $\begin{array}{l}\text { N. heart size; } \\
\text { slight dilat. } \\
\text { asc. aorta }\end{array}$ & Normal \\
\hline J.C. & $\mathbf{F}$ & 27 & Slight fatigue & $\mathbf{S}$ & $\mathbf{N}$ & + & $\underset{4}{\text { Grade }}$ & 一 & $\begin{array}{l}\text { N. heart size; } \\
\text { slight dilat. } \\
\text { asc. aorta }\end{array}$ & L.A.D. \\
\hline J.R. & $\mathbf{M}$ & 27 & Slight fatigue & $\mathbf{S}$ & + & + & $\underset{3}{\text { Grade }}$ & $\begin{array}{c}\text { Grade } \\
1\end{array}$ & $\begin{array}{l}+ \text { heart size } \\
+ \text { L.V. } \\
\text { Round left bor- } \\
\text { der } \\
+ \text { dilat. asc. } \\
\text { aorta }\end{array}$ & L.V.H. \\
\hline M.A.G. & $\mathbf{F}$ & 12 & $\begin{array}{c}\text { Minimal fatigue } \\
\text { and dyspnoea }\end{array}$ & $\mathbf{N}$ & $\mathbf{N}$ & + & $\begin{array}{c}\text { Grade } \\
4\end{array}$ & - & $\begin{array}{l}++ \text { heart size } \\
+ \text { L.V. } \\
\text { Round and } \\
\text { elong. left } \\
\text { border }\end{array}$ & L.V.H. \\
\hline B.O. & $\mathbf{F}$ & 17 & Slight dyspnœa & $\mathbf{S}$ & $\mathbf{N}$ & + & $\underset{3}{\text { Grade }}$ & - & $\begin{array}{l}+ \text { heart size } \\
+ \text { L.V. } \\
+ \text { dilat. asc. } \\
\text { aorta }\end{array}$ & L.V.H. \\
\hline J.G. & $\mathbf{M}$ & 11 & None & $\mathbf{N}$ & $\mathbf{N}$ & + & $\underset{3}{\text { Grade }}$ & - & $\begin{array}{l}++ \text { heart size } \\
+ \text { L.V. } \\
\text { Round elong. } \\
\text { border }\end{array}$ & L.V.H. \\
\hline
\end{tabular}

Key to abbreviations: $M=$ male; $F=$ female; $N$.=normal; $S=$ split; L.V.H.=left ventricular hypertrophy; L.A.=left atrium; L.V.=left ventricle; B.A.=brachial artery; P.A.=pulmonary artery; R.V.=right ventricle; R.A.=right atrium; C.O.=cardiac output; A.V.F.=aortic valve flow; A.V.A.=aortic valve area; SE sec.=systolic ejection second; B.A.V.= bicuspid aortic valve.

* All the operations were performed by Dr. C. P. Bailey at the Bailey Thoracic Clinic. 


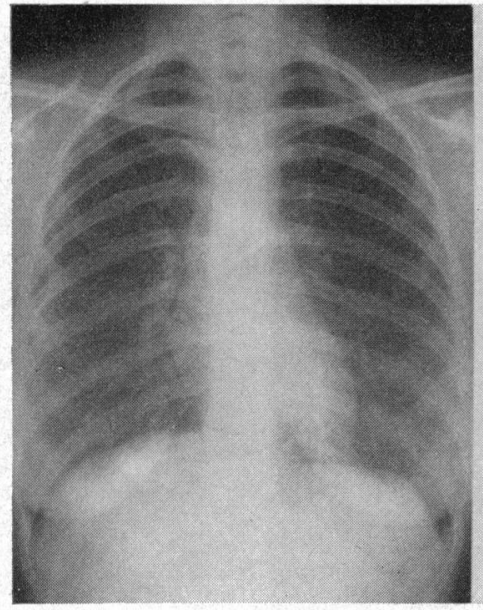

A

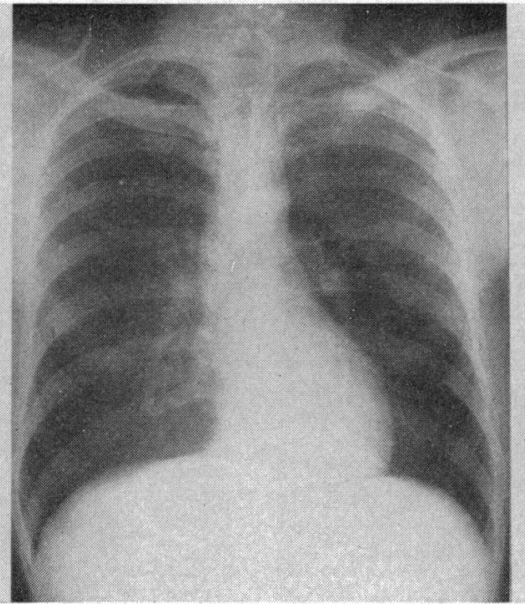

B

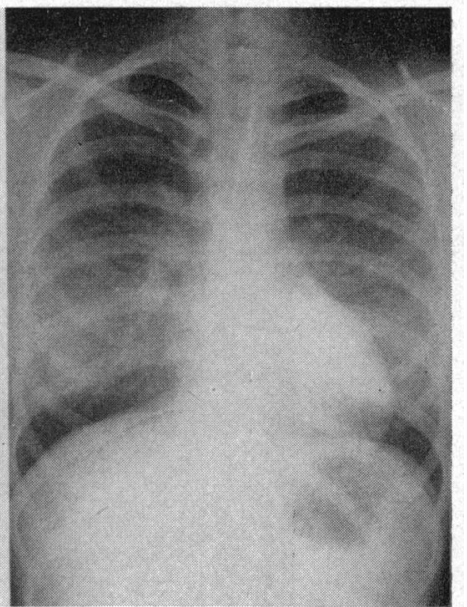

C

FIG. 1.-(A) Normal heart size and slight dilatation of the ascending aorta in patient J.C. with left axis deviation in an otherwise normal electrocardiogram, small aortic gradient, and minimal fusion of both aortic commissures. (B) Rounding of the left cardiac border and dilatation of the ascending aorta in patient J.R. with early left ventricular hypertrophy in the electrocardiogram, moderate aortic gradient, and slight fusion of both aortic commissures; (C) Left ventricular enlargement in patient M.A.G. with left ventricular hypertrophy in the electrocardiogram, moderate aortic gradient, and moderate fusion of the commissures.

murmur in the same area. The murmur constantly radiated with decreased intensity to the neck, left sternal border, and apex and, rarely, to the back. The second aortic sound was normal or accentuated and the second pulmonary sound normal in all patients. The mitral first sound was normal in three and split in the other three. A faint, early blowing diastolic murmur was heard along the left sternal border in one case (Table I).

The size of the heart was normal in two (R.T. and J.C.), $1+$ in two, and $2+$ in two patients on the basis of 1 to $4+$ grading. The contour of the left cardiac border was normal in two (R.T. and J.C.) and elongated and/or rounded in four with a normal to $1+$ left ventricle. Some dilatation of the ascending aorta was noticed in four patients while the aortic knob and the pulmonary vascular markings were normal in all (Table I and Fig. 1). No aortic valve calcification was observed.

The electrocardiogram was normal in one patient (R.T.) and left axis deviation was present in a second (J.C.). Four patients had clear-cut evidence of left ventricular hypertrophy as judged by the presence of flatness or inversion of the T wave and, less frequently, of RS-T segment depression and/or increased voltage of the QRS complex in the leads facing the left ventricle (Table I and Fig. 2).

The intracardiac pressures were normal in all six patients. "Of the five in whom left heart catheterization was performed, a left ventricular to brachial artery systolic ejection pressure gradient was absent in one (R.T.) and slight to moderate in four, not exceeding $43 \mathrm{~mm}$. $\mathrm{Hg}$. The calculated aortic valve area was $0.8,0.9$, and $1.2 \mathrm{~cm} .{ }^{2}$ in the three patients in whom it was measurable (Table II and Fig. 3).

In one case (R.T.) with normal radiogram and electrocardiogram and no pressure gradient across the aortic valve, the orifice at surgery did not show any evidence of commissural fusion. Patient J.C. with normal size heart, left axis deviation on the electrocardiogram, and a small aortic gradient presented minimal fusion of both commissures. Of the remaining four patients with 1 or $2+$ cardiac enlargement, electrocardiographic evidence of left ventricular hypertrophy, and moderate aortic gradients, one showed slight, and one moderate, bilateral commissural fusion, the third had a unilateral fusion which extended beyond the midline producing an eccentric, tear-drop orifice, and the last showed marked bilateral stenosis. In this patient what appeared to be a rudimentary left 
coronary cusp could be seen in the fused tissue of the left anterior commissure. In addition, an aneurysm of the sinus of Valsalva of the right coronary cusp was present and considered by the surgeon as secondary to the impact of the jet of blood on the aortic wall during left ventricular ejection (Table II).

A

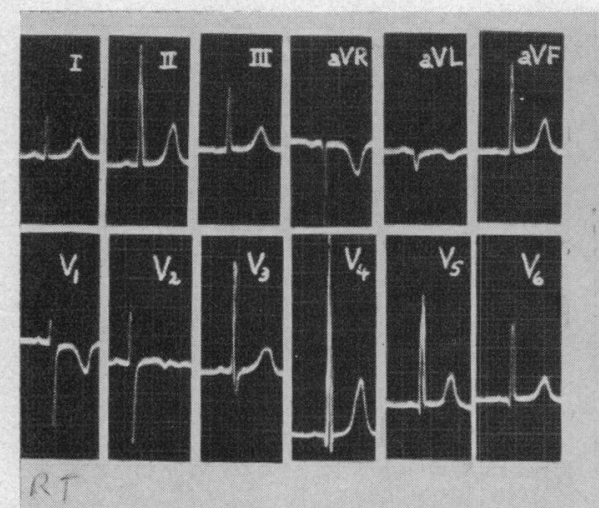

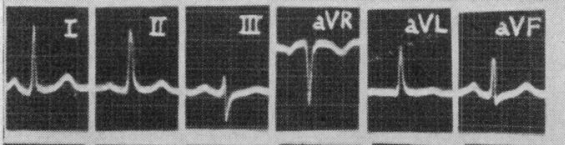
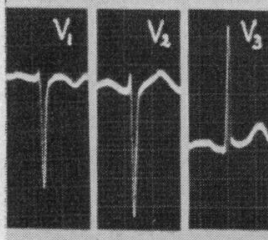

$V_{3} \mid V_{4}$

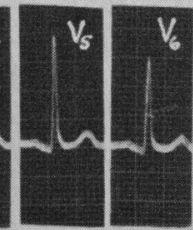

JC

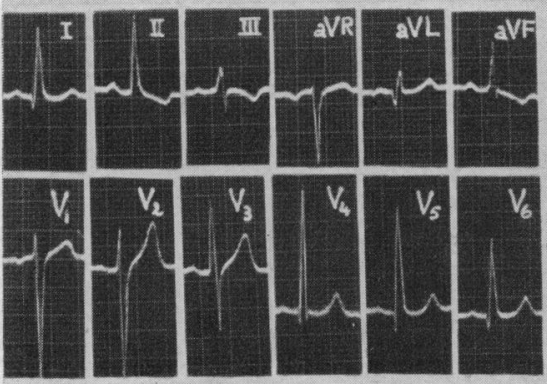

T.
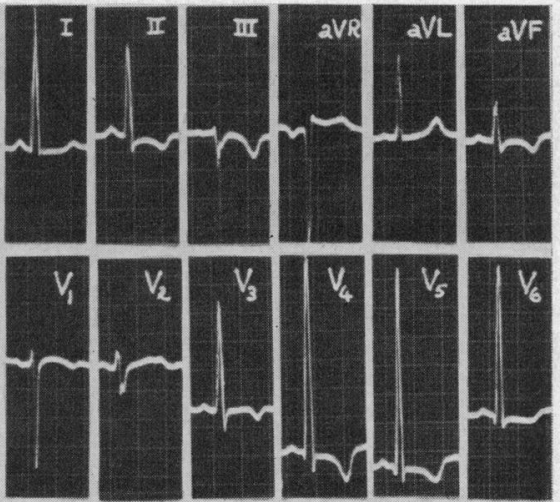

B
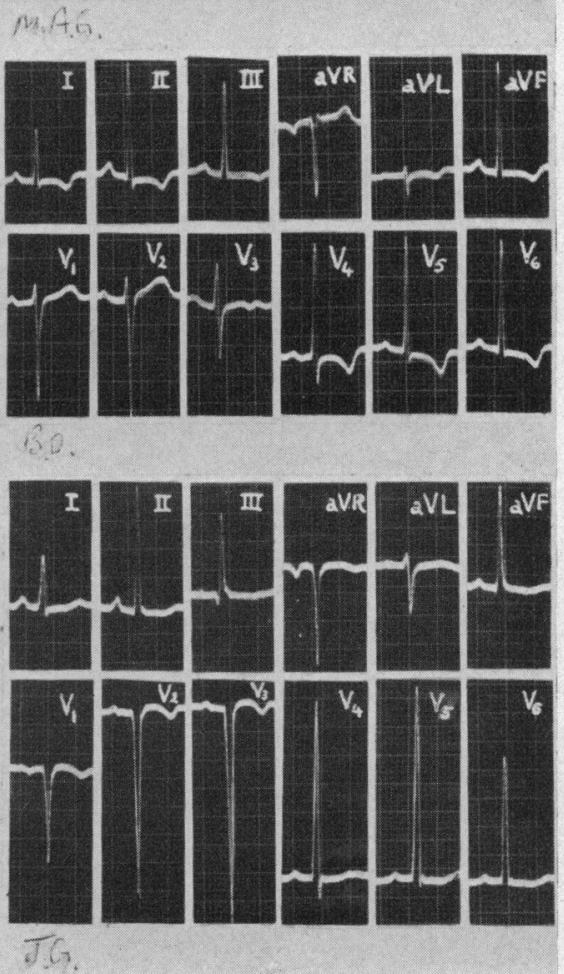

FIG. 2.-(A) Normal electrocardiogram in patient R.T.; left axis deviation in patient J.C.; $T$ wave inversion in lead II, III, and aVF in a semi-vertical heart, and upright $T$ wave in aVR consistent with early left ventricular hypertrophy in patient J.R. (B) All three tracings display evidence of RS-T segment depression and/or T wave flatness or inversion in the leads facing the left ventricle and are indicative of left ventricular hypertrophy. (Some of the tracings are retouched.) 
TABLE II

Cardiac Catheterization Data in Six Patients with Bicuspid Aortic Valve

\begin{tabular}{|c|c|c|c|c|c|c|c|c|c|c|c|}
\hline \multirow{2}{*}{ Name } & \multicolumn{6}{|c|}{ Pressures $(\mathrm{mm} . \mathrm{Hg})$} & \multirow{2}{*}{$\begin{array}{l}\text { L.V.-B.A. } \\
\text { gradient } \dagger \\
\text { (mm. Hg) }\end{array}$} & \multirow{2}{*}{$\mid \begin{array}{c}\text { C.O. } \\
(1 . / \text { min. })\end{array}$} & \multirow{2}{*}{$\begin{array}{l}\text { A.V.F. } \\
\text { (c.c./S.E. } \\
\text { sec.) }\end{array}$} & \multirow{2}{*}{$\begin{array}{l}\text { A.V.A. } \\
\left(\mathrm{cm} .{ }^{2}\right)\end{array}$} & \multirow{2}{*}{ Operative findings } \\
\hline & L.A. & L.V. & B.A. & P.A. & R.V. & R.A. & & & & & \\
\hline R.T. & - & $\frac{96}{3}$ & $\frac{96}{62}(74)^{*}$ & $\frac{13}{7}(10)$ & $\frac{13}{2}$ & (3) & 0 & - & - & - & $\begin{array}{l}\text { Bicuspid aortic valve } \\
\text { (B.A.V.) }\end{array}$ \\
\hline \multirow[t]{2}{*}{ J.C. } & (9) & $\frac{140}{5}$ & $\frac{112}{69}(85)$ & $\frac{13}{6}(10)$ & $\frac{13}{-1}$ & $(-1)$ & 14 & $4 \cdot 1$ & 186 & $1 \cdot 2$ & \multirow{2}{*}{$\begin{array}{l}\text { B.V.A. } \\
\text { Minimal fusion of } \\
\text { both commissures, } \\
\text { more pronounced at } \\
\text { the antero-medial }\end{array}$} \\
\hline & (4) & $\frac{145}{2}$ & $\frac{99}{67}(78)$ & $\frac{20}{-2}$ & $\frac{20}{-2}$ & (1) & 40 & - & - & - & \\
\hline J.R. & (7) & $\frac{146}{8}$ & $\frac{108}{58}(78)$ & - & - & - & 38 & - & - & - & $\begin{array}{l}\text { B.V.A. } \\
\text { Slight fusion of both } \\
\text { commissures }\end{array}$ \\
\hline M.A.G. & $(10)$ & $\frac{150}{9}$ & $\frac{105}{67}(78)$ & - & $\frac{24}{1}$ & (1) & 30 & $3 \cdot 5$ & 185 & $0 \cdot 8$ & $\begin{array}{l}\text { B.A.V. } \\
\text { Moderate fusion of } \\
\text { both commissures }\end{array}$ \\
\hline B.D. & (1) & $\frac{138}{5}$ & $\frac{73}{38}(47)$ & $\frac{20}{6}(11)$ & $\frac{26}{3}$ & (0) & 43 & $5 \cdot 3$ & 258 & 0.9 & $\begin{array}{l}\text { B.A.V. } \\
\text { Complete fusion } \\
\text { of a ntero-medial } \\
\text { comm. with eccen- } \\
\text { tric tear-drop orifice }\end{array}$ \\
\hline J.G. & - & - & $\frac{105}{80}(87)$ & $\frac{20}{5}(12)$ & $\frac{20}{0}$ & (0) & - & - & - & - & $\begin{array}{l}\text { B.A.V. } \\
\text { Marked fusion of } \\
\text { both comm. Aneu- } \\
\text { rysm of the sinus } \\
\text { Valsalvæ. Rudi- } \\
\text { mentary left coro- } \\
\text { nary leaflet }\end{array}$ \\
\hline
\end{tabular}

* Aortic pressure.

$\uparrow$ Gradients measured by planimetry.

\section{DiscUSSION}

Congenital bicuspid aortic valve when associated with other congenital cardiac lesions is probably the most common single malformation of them all (Koletsky, 1941). It occurred in $18(29 \%)$ of 63 necropsies in the series by Koletsky (1941) and in $11(21 \%)$ of 52 in the series of Tranchesi et al. (1954). Koletsky estimates its incidence at between 0.5 and 1 per cent of all necropsies.

The frequent association with coarctation of the aorta is well recognized (Abbott, 1928; Smith and Matthews, 1955; Keith et al., 1958). Even as an isolated lesion its incidence appears to be significant: it was present in 9 of the 18 cases of the series by Koletsky and in 8 of the 11 by Tranchesi et al., mentioned above.

The frequent development of subacute bacterial endocarditis as a complication in this condition has been perhaps over-stressed (Lewis and Grant, 1923). The occurrence of this infection in patients with no previous history or symptoms of heart disease has constituted so far the only indirect criterion for the tentative clinical diagnosis of congenital bicuspid aortic valve (Bourne, 1946; Tranchesi et al., 1954). This approach implicitly recognizes the great difficulty of reaching even a tentative diagnosis of bicuspid aortic valve in the absence of complicating subacute bacterial endocarditis. Yet this series, showing no past or present evidence of subacute bacterial endocarditis, shows that uncomplicated congenital bicuspid aortic valve is not rare, confirming thereby a previous report (Koletsky, 1943). 


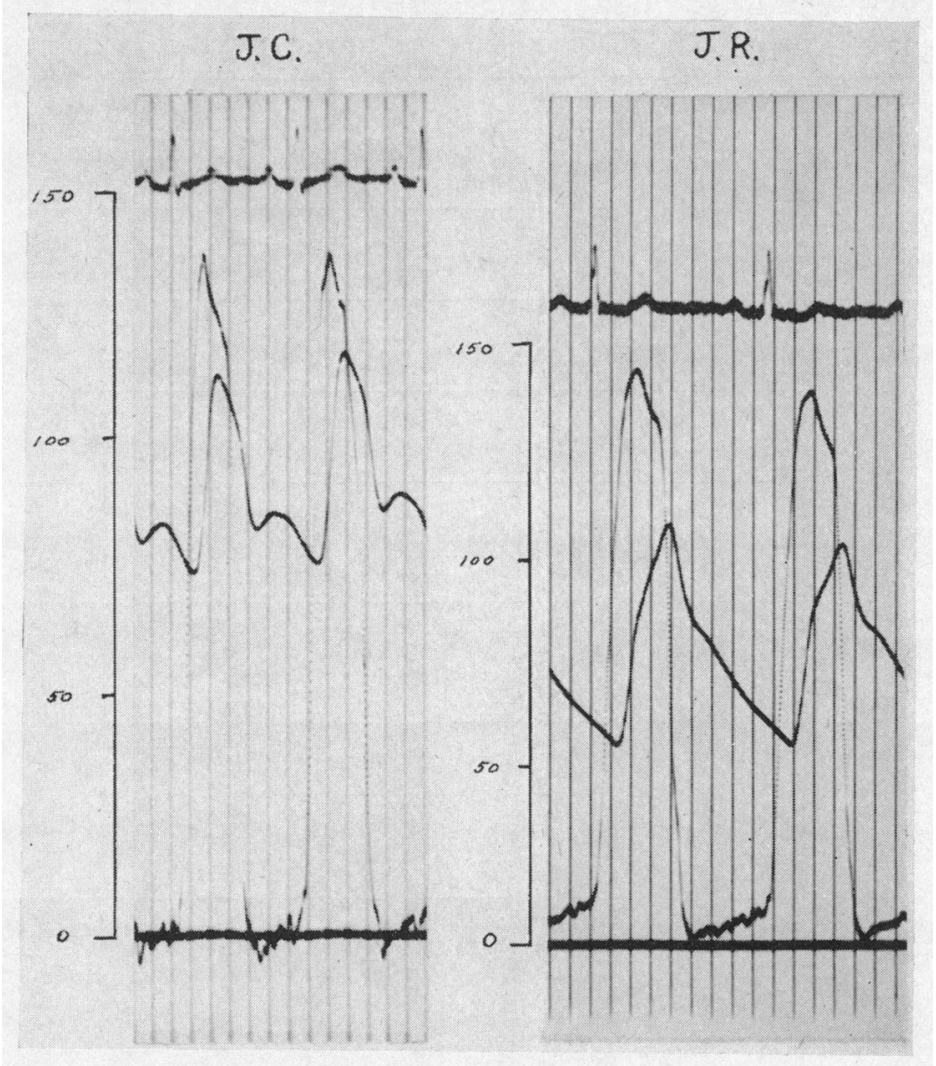

FIG. 3.-Simultaneous pressure recordings from the left ventricle and brachial artery, showing respectively a small and moderate aortic systolic ejection pressure gradient in patients J.C. and J.R.

The need for improved diagnostic refinement is recognized. The statement by Tranchesi et al. that uncomplicated bicuspid aortic valve is impossible to diagnose because "when present as an isolated finding (it) does not give rise to a hæmodynamic disturbance and consequently produces no clinical signs" cannot be accepted on the basis of the data at hand.

The assumption of a congenital origin of the cases herein reported is justified by the absence of a history of rheumatic fever or of any other major illness and by the discovery of a murmur before the age of five. The rarity of rheumatic fever before this age is well known (Hedley, 1940; Cohn and Lingg, 1943). The preponderance of male over female cases, frequently emphasized, is not encountered in the present series which is, however, too small to justify any comment.

In previous reports dealing with congenital aortic stenosis including bicuspid aortic valve stenosis the absence of symptoms or their extreme mildness when present, even in the face of severe obstruction has been stressed and the conclusion has been drawn that negative symptomatology does not bespeak trivial pathology (Marquis and Logan, 1955). This finding is common to the present series but, in the light of the generally mild dynamic derangement, its interpretation may be different. The awareness of a murmur present since childhood, combined with the frequently imposed reduction of physical activity, suggests an iatrogenic origin of symptoms in some, at least, of the present cases. This is certainly true for the fatigue of patient R.T., not justified by altered cardiac dynamics. The exertional dyspnœa of patient B.O., on the other part, can be explained by her obesity.

Concerning physical findings a problem arises immediately, namely the occurrence of an aortic 
systolic murmur in patients with a non-stenotic bicuspid aortic valve. In reviewing the previously reported cases only two were encountered in which no such murmur was audible. They are cases three and four of the series of uncomplicated bicuspid aortic valve reported by Lewis and Grant (1923) the latter of which had a systolic murmur at the apex. The possibility that murmurs were overlooked in these two cases has to be entertained because the paper was mainly pathological, with clinical data obtained from the records, and also because of the irregularity and thickness and (in one of the two cases) calcification of the free margins of the aortic cusps. The only case of the present series with normal dynamics and a non-stenotic bicuspid aortic valve presented a systolic thrill and a grade 3 rough systolic murmur at the aortic area. From these premises one would be inclined to conclude that a bicuspid aortic valve is the natural site of origin of the systolic murmur and thrill. The dynamic equivalent of the murmur would be the turbulence generated within the stream of blood during its passage through a linear or elliptical, instead of circular, orifice. The presence of a murmur in all cases of congenital bicuspid aortic valve would greatly facilitate the recognition of such a malformation. This thesis, unfortunately, remains to be proven at the present time, though it is hoped that the accumulation of more clinical, surgical, and pathological material will confirm its validity. Congenital bicuspid aortic valves appear to be quite competent, if not affected by subacute bacterial endocarditis or associated with coarctation of the aorta, as demonstrated by the presence of a murmur of aortic regurgitation with no peripheral signs of this in only one of the present cases.

The normal and, in one instance, increased intensity of the second aortic sound in the present series, is in agreement with the general consensus of recent reports on congenital aortic stenosis (Kiloh, 1950; Lewis, 1951; Reinhold et al., 1955). Splitting or apparent accentuation of the first heart sound at the apex has been already observed by others and attributed to rapid succession or super-imposition of an early aortic systolic ejection sound on the sound produced by the mitral valve closure (Marquis and Logan, 1955; Reinhold et al., 1955) (Fig. 4).

It has been stated by many (Marquis and Logan, 1955; Kiloh, 1950; Campbell and Kauntze, 1955) that the degree of obstruction in congenital aortic stenosis may be considerable without any enlargement of the heart. It was concluded that radiology is of limited value in assessing and grading the severity of this lesion. In the present series the heart size was normal in the two patients with either a negligible or no aortic systolic ejection gradient (R.T. and J.C.) while progressive increases in heart size were associated with obstructions of greater dynamic significance.

Electrocardiography is commonly recognized as an important diagnostic aid in the evaluation of an aortic systolic murmur. Its value is confirmed in the present study. A normal electrocardiogram was recorded in the patient with an uncomplicated bicuspid aortic valve, while left axis deviation was present in patient J.C. with a small aortic ejection gradient. The pattern of left ventricular hypertrophy was unvariably found in the cases with a moderate aortic ejection gradient.

In the light of the present limited experience the uncomplicated bicuspid aortic valve does not seem to produce hæmodynamic changes. However, in the presence of associated aortic stenosis slight or moderate systolic ejection gradients across the aortic valve were found in this series. The steepness of this gradient appears to be conditioned by the extent of the commissural fusion and the degree of stiffness and thickening of the valve leaflets. The end diastolic pressure in the left ventricle was not elevated. The cardiac output and aortic valve flow were normal in all and aortic valve areas were only moderately reduced.

Such findings are in agreement with the experimental work of Wiggers (1947) showing that the aortic orifice has to be reduced to one-fourth of its original size before the dynamics become altered across the aortic valve. In a clinical series of patients with advanced rheumatic aortic stenosis and with symptoms the average aortic valve area was reduced to about $0.5 \mathrm{~cm} .{ }^{2}$ (Goldberg et al., 1958).

It is of interest to note that in patient J.C. a repeat left heart catheterization performed two years after an initial study, showed an appreciable increase in the aortic ejection gradient. The increase of stroke volume, known to occur with growth, cannot be held reponsible for the increased gradient in this case, owing to her adult age. In the absence of changes in the basal condition during either 


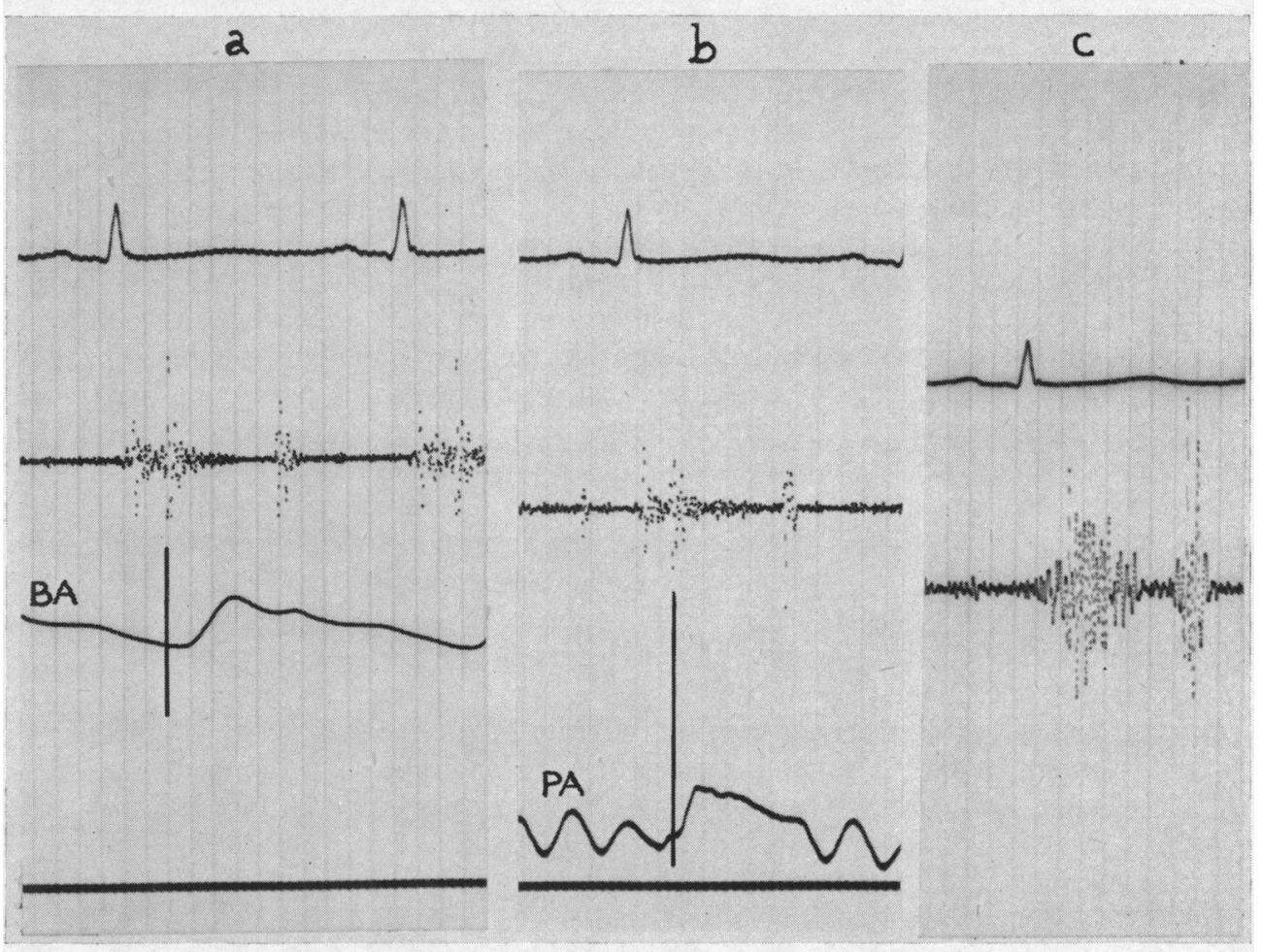

FIG. 4 (A and B) Splitting of the first sound on the phonocardiogram recorded from the mitral area. The second component of the first sound is synchronous with the beginning of the anacrotic phase of the pulmonary artery pulse, while preceding that of the brachial artery pulse by approximately $0.04 \mathrm{sec}$. Allowing for the delay of conduction of the pressure wave from the heart to the manometer, the added sound appears to be a systolic click related to the opening of the aortic valve. (C) In the tracing from the aortic area the systolic murmur is loud while the splitting is not apparent.

Speed of the paper $75 \mathrm{~mm}$./sec.; time interval $0.04 \mathrm{sec}$; sensitivity $10 \mathrm{~mm} . / \mathrm{mv}$. PA= Pulmonary artery; $\mathrm{BA}=$ Brachial artery.

of the two physiological studies a further narrowing of the aortic orifice has to be postulated. This is in agreement with previous statements (Peacock, 1865; Smith and Matthews, 1955; Marquis and Logan, 1955). Finally the pulmonary circuit in this series, as expected, did not show any abnormalities.

The finding of commissural fusion in the majority of the present cases seems to indicate that congenital bicuspid aortic valves are very frequently associated with congenital or acquired stenosis. Either alternative cannot be discarded at the present time although several authors (Peacock, 1865; Smith and Matthews, 1955; Marquis and Logan, 1955) favour the hypothesis of an acquired narrowing. Even the adults of this series showed no calcification of the aortic cusps, which were relatively normal in appearance, the commissural fusion being produced by smooth, regular fibrous tissue. These findings suggest that valvular degeneration and calcification may represent late events in the devolutionary process of this congenital malformation.

The correlation between electrocardiographic, radiological, physiological, and surgical findings was impressive in the present series. Patient R.T., for instance, with the evidence of an uncomplicated bicuspid aortic valve showed normal radiograms and electrocardiogram and absence of an aortic ejection pressure gradient. The remaining five patients with progressive degrees of commissural fusion showed a progressive deterioration of these parameters. On these bases, the 
findings at the operating table in the last cases were anticipated. As a matter of fact, patient R.T. had not been considered for operation and only upon pressing insistence on the part of his parents was the aortic valve explored.

Congenital bicuspid aortic valve stenosis appears to play a more important role in the group of congenital aortic stenosis than has been so far recognized. It is noted that in Campbell's series of congenital aortic stenosis one of the two available autopsies revealed the existence of a bicuspid aortic valve; of two additional necropsies, one was thought to present the same lesion. In the paper by Marquis and Logan two of the three available autopsies ( 6 and 11 years old) showed a bicuspid aortic valve stenosis. Finally in the series by Sagarminaga et al. (to be published) 39 per cent of the cases of congenital aortic stenosis involved a bicuspid aortic valve.

\section{SUMMARY AND CONCLUSION}

Six proven cases of congenital bicuspid aortic valve are presented and the clinical and hæmodynamic features of this malformation are reviewed. It is concluded that an isolated bicuspid aortic valve represents a benign entity if its function is not compromised by commissural fusion or pathological changes which limit valvular patency or mobility. A bicuspid valve does not open ideally; yet this does not seem to produce elevation of the systolic ejection pressure in the left ventricle, development of a systolic ejection pressure gradient across the aortic valve, or increase in left ventricular work. It is believed, however, to be responsible for the creation of sufficient turbulence in the ascending aorta to give rise to a rough systolic murmur and dilatation of this vessel as shown by $\mathrm{X}$-ray. The second aortic sound is of normal intensity as a general rule. Left ventricular hypertrophy does not appear on radiological or electrocardiographic examination.

In contrast to this picture the addition of commissural fusion and intrinsic pathological changes within the leaflets leads to many clinical and hæmodynamic alterations. A wide range of intermediate stages is possible between an isolated congenital bicuspid and a funnel shaped, monocuspid aortic valve. As the bicuspid aortic valve becomes narrowed by changes of congenital or acquired nature a systolic ejection pressure gradient across the valve appears and the increased left ventricular work is reflected by the development of left ventricular hypertrophy on $\mathrm{X}$-ray and electrocardiogram. The second aortic sound, in the absence of calcification, is normal. These objective changes precede the onset of symptoms.

Stenosis of a congenital bicuspid aortic valve represents a greater portion of the group of congenital aortic stenosis than is commonly recognized.

\section{REFERENCES}

Abbott, M. E. (1928). Amer. Heart J., 3, 392.

Bettini, U. (1957). Arch. De Vecchi Anat. pat., 25, 613.

Björk, V. O., Malmstrom, G., and Uggla, L. G. (1953). Ann. Surg., 138, 718.

Bougas, J., Musser, B. G., and Goldberg, H. (1956). Amer. Heart J., 52, 359.

Bourne, G. (1946). Brit. med. J., 1, 609.

Campbell, M., and Kauntze, R. (1955). Brit. Heart J., 15, 179.

Cohn, A. E., and Lingg, C. (1943). J. Amer. med. Ass., 121, 1.

Cournand, A., and Ranges, H. A. (1941). Proc. Soc. exp. Biol., (N.Y.), 46, 462.

Denie, J. J., and Verheugt, A. D. (1958). Circulation, 28, 902.

Goldberg, H., Dickens, J., Raber, G., and Hayes, E. (1957). Amer. Heart J., 53, 579.

, Denton, C., Bender, S., and Uricchio, J. (1958). Dis. Chest, 33, 201.

Gorlin, R., and Gorlin, S. G. (1951). Amer. Heart J., 41, 1.

Günsburg, F. (1846). Arch. ges. Med., 8, 299.

Hedley, O. F. (1940). Publ. Hlth Rep. (Wash.), 55, 1647.

Keith, J.D., Rowe, R. D., and Vlad, P. (1958). Heart Disease in Infancy and Childhood. The MacMillan Company, New York.

Kiloh, G. A. (1950). Brit. Heart J., 12, 33.

Koletsky, S. (1941). Arch. intern. Med., 67, 129.

- (1943). Amer. Heart J., 26, 243.

Kossman, C. E., and Johnston, F. D. (1935). Amer. Heart J., 10, 925.

Lewis, D. (1951). Brit. med.J., 1, 211.

Lewis, T., and Grant, R. T. (1923). Heart, 10, 25 and 43. 
Marquis, R. M., and Logan, A. (1955). Brit. Heart J., 17, 373.

Osler, W. (1866). Trans. Ass. Amer. Phycns., 1, 185.

Peacock, T. B. (1865). On some of the Causes and Effects of Valvular Disease of the Heart. J. Churchill \& Sons, London.

(1866). On Malformations of the Human Heart. Second edition. J. Churchill \& Sons, London.

Reinhold, J., Rudhe, U., and Bonham Carter, R. E. (1955). Brit. Heart J., 17, 327.

Sagarminaga, J., Bentivoglio, L., and Uricchio, J. (To be published.)

Smith, D. E., and Matthews, M. B. (1955). Brit. Heart J., 17, 198.

Sokolow, M., and Lyon, T. P. (1949). Amer. Heart J., 37, 161.

Tranchesi, J., Carrol, R., De Amorim, I., and Peñaloza, D. (1954). Amer. Heart J., 47, 664.

Van Slyke, D. D., and Neill, J. M. (1924). J. biol. Chem., 61, 523.

Wiggers, G. J. (1947). Physiology in Health and Disease, 5th edition. Lea and Febiger, Philadelphia. 